\title{
Laboreal
}

Volume $11 \mathrm{~N}^{\circ} 1$ | 2015

Modos de vida e trabalho

\section{Ingresso, permanência e abandono na profissão de motoboys: constituição de si e da profissão}

Ingreso, permanencia y abandono en la profesión de mensajero motociclista: constitución de sí y de la profesión

Entrée, permanence et abandon dans la profession de courrier motocycliste: constitution de soi et de la profession

Entrance, permanence and abandonment in the motorcycle couriers' profession: constitution of oneself and of the profession

Thiago Drumond Moraes, Roseane Vargas Rohr and Milton Athayde

\section{(2) OpenEdition}

Journals

Electronic version

URL: http://journals.openedition.org/laboreal/4244

DOI: $10.4000 /$ laboreal.4244

ISSN: 1646-5237

\section{Publisher}

Universidade do Porto

Electronic reference

Thiago Drumond Moraes, Roseane Vargas Rohr and Milton Athayde, «Ingresso, permanência e abandono na profissão de motoboys: constituição de si e da profissão », Laboreal [Online], Volume 11 $N^{0} 1$ | 2015, Online since 09 September 2019, connection on 09 October 2019. URL : http:// journals.openedition.org/laboreal/4244; DOI : 10.4000/laboreal.4244

This text was automatically generated on 9 October 2019.

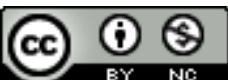

Laboreal está licenciado com uma Licença Creative Commons - Atribuição-NãoComercial 4.0 Internacional. 


\section{Ingresso, permanência e abandono na profissão de motoboys: constituição de si e da profissão}

Ingreso, permanencia y abandono en la profesión de mensajero motociclista: constitución de sí y de la profesión

Entrée, permanence et abandon dans la profession de courrier motocycliste: constitution de soi et de la profession

Entrance, permanence and abandonment in the motorcycle couriers' profession: constitution of oneself and of the profession

Thiago Drumond Moraes, Roseane Vargas Rohr and Milton Athayde

\section{EDITOR'S NOTE}

http://dx.doi.org/10.15667/laborealxi0115tdm

Manuscrito recebido em: novembro de 2014

Aceite após peritagem: abril de 2015

\section{AUTHOR'S NOTE}

Projeto financiado pela FAPES/ES, Brasil.

\section{Introdução}

1 Dados epidemiológicos indicam aumento de óbitos envolvendo condutores e ocupantes de motocicletas entre 2000 e 2012 no Brasil. Embora estes dados não façam a necessária distinção, esse aumento pode estar relacionado às atividades de trabalho dos 
profissionais que se passaram a denominar "motoboys" (Bacchieri \& Barros, 2011), profissão que vem sendo analisada por alguns pesquisadores (Diniz, 2003; Oliveira, 2003; Veronese, 2004; Silva, 2006; Grisci, Scalco \& Janovik, 2007; Moraes, 2008; PaesMachado \& Riccio-Oliveira, 2009; Silva, 2010; Kieling et al., 2011; Soares, Mathias, Silva \& Andrade, 2011). Essa profissão emerge no Brasil em meados da década de 1980, ganhando maior expressão durante as duas décadas seguintes, quando se fizeram sentir de modo mais marcante no país as transformações características do capitalismo contemporâneo, transformações essas que se compreende, não sem debates, pelos nomes de acumulação flexível, pós-industrialização, pós-modernidade, pósmodernismos, entre outros (Harvey, 1992; Kumar, 1997; Cocco, 2000; Bauman, 2001; Hardt \& Negri, 2001). Trata-se de uma profissão que se caracteriza pelo serviço de transporte de documentos, alimentos e objetos, tendo como veículo a motocicleta, cujo uso se tornou estratégico no Brasil seja em função do trânsito cada vez mais volumoso e lento, da flexibilidade desses veículos, seja pelo seu reduzido custo de aquisição e manutenção em relação aos veículos de quatro ou mais rodas. Em geral o serviço prestado pelos motoboys é disparado por demandas de algum tipo de cliente (pessoa física ou jurídica) localizado em algum lugar da cidade que requeira determinado produto ou serviço de um fornecedor estabelecido em outro local e que não pretenda ou não possa deslocar-se até lá. É o motoboy que garante a prestação desse serviço até o cliente contratante. 0 exemplo mais emblemático é a encomenda de pizzas por clientes que preferem consumi-las em suas casas ou locais de trabalho, tendo nos motoboys o meio de transporte do produto em tempo hábil. Entretanto, além de alimentos, a prestação de serviço envolve uma ampla diversidade de objetos, em sua maior parte documentos e valores em espécie, produtos automotivos, exames laboratoriais e botijões de gás. Ao longo dos anos 2000, a quantidade de trabalhadores exercendo essa ocupação, bem como o elevado número de acidentes a ela relacionados, despertaram a atenção dos poderes públicos e da comunidade acadêmico-científica. Iniciou-se naquele momento um debate sobre essa profissão, que culminou com sua regulamentação em 2009 (Lei $\mathrm{n}^{\mathrm{0}} 12.009$, de 29 de julho de 2009), ao mesmo tempo em que se observava nas universidades uma série de investigações sobre a problemática. Em paralelo, ocorreu um movimento similar, de utilização de motocicletas para o transporte de pessoas, serviço esse que vem sendo denominado "mototaxi" e que vem sendo também objeto de uma série de regulamentações jurídicas e produções acadêmicas. A regulamentação supracitada refere-se a ambas profissões, motoboys e mototaxistas. Quanto à produção acadêmica, ela vem ocorrendo em paralelo, por mais próximas sejam as profissões. No presente texto, nos dedicamos especificamente à profissão dos motoboys e à literatura pertinente a eles. Para a literatura sobre mototaxistas, ver: Luna e Oliveira (2011); Silva, Oliveira e Fontana (2011), e Amorim, Araujo, Araújo e Oliveira (2012).

2 Entre as investigações sobre motoboys a que tivemos acesso, elas se dedicaram, sobretudo, à identificação das possíveis relações entre condições físicas, organizacionais, econômicas e políticas do trabalho (percebidas como precárias), assim como seus efeitos nocivos sobre os trabalhadores, especialmente quanto ao quadro de morbimortalidade. Verificou-se que os motoboys convivem cotidianamente com acidentes de trabalho (Silva, Soares \& Andrade, 2008), relacionados a modos de remuneração por produção, condições das vias, fragilidade das relações profissionais e do coletivo de trabalho, pressão por horas extras de trabalho e grande rotatividade na profissão, entre outros fatores (Diniz, 2003; Silva, 2006; Moraes, 2008; Silva et al., 2008). Diante desse quadro, poder-se-ia supor que os profissionais compartilhariam 
percepções negativas sobre essa ocupação, o que justificaria, por exemplo, a alta rotatividade.

3 Não obstante, investigações de cunho antropológico indicam que parte dos trabalhadores avalia positivamente a sua profissão (Neto, Mutaf \& Avlasevicius, 2006), sugerindo-nos que, por meio das atividades que a compõe, desenvolvem-se também aspectos subjetivos e sociais que, em sua positividade, devem ser melhor conhecidos. Entre estes, encontram-se as produções identitárias, as dimensões que envolvem as normas, valores, saberes, processos cognitivos e sócio-afetivos gerados e partilhados no curso das atividades, as dinâmicas de ingresso e permanência/abandono da profissão, assim como as relações sociológicas entre trabalho e regulamentação profissional.

Esses aspectos são importantes por contribuir para a compreensão mais precisa das atividades de trabalho desses profissionais. Tomando-se como referência teórica as concepções propostas pela Ergonomia da Atividade (Falzon, 2007), em particular a permanente defasagem entre tarefa prescrita e atividade realizada, verifica-se que as condições de trabalho se referem não só às dimensões contextuais em que um trabalho se realiza, como também às condições das pessoas (Leplat \& Cuny, 1998), já que os trabalhadores - no momento da atividade - são mobilizados, inevitavelmente, para garantir que as variabilidades de todo tipo que se apresentam quando da execução das tarefas, sejam devidamente reguladas. Nessa mobilização, os trabalhadores consideram tanto as exigências da prescrição, quanto a realização das suas expectativas em relação à profissão, saúde e vida. Além disso, tais expectativas contribuem para auxiliar nos processos decisórios e nas mobilizações sócio-cognitivas e corporais a que são convocados cotidianamente na execução das tarefas, bem como se relacionam aos efeitos das atividades nos próprios sujeitos. Por essa razão, entende-se que é fundamental compreender melhor tais expectativas e a situação das pessoas que estão nesta profissão, identificando como ingressam e, eventualmente, aí se desenvolvem. A compreensão desse cenário pode permitir orientar práticas de intervenção positiva junto a esse grupo profissional.

5 Visando contribuir para o encaminhamento dessas questões, com este artigo objetivase apresentar o processo de ingresso, permanência e/ou abandono de trabalhadores na profissão de motoboys, tendo como base empírica a realidade da cidade de Vitória, capital do estado do Espírito Santo, estado da região Sudeste do Brasil. Busca-se também revelar alguns dos efeitos desse processo, tanto no plano da produção de subjetividade, quanto na dimensão coletiva do trabalho. Compreender melhor esses processos pode dar visibilidade às condições e formas de organização do trabalho atualmente existentes neste campo e o que se revela urgente: contribuir com a (re)formulação de políticas públicas que tanto favoreçam as demandas destes profissionais quanto as da sociedade. 0 que certamente só terá efeito caso elas lhes façam sentido.

6 Para apreender tais fenômenos tivemos como orientação geral a démarche proposta pela Ergologia (Durrive \& Schwartz, 2008; Schwartz \& Durrive, 2010), mobilizando parcialmente a abordagem transdisciplinar operada pela Ergonomia da Atividade (Falzon, 2007), e no plano da análise psicológica do trabalho as correntes clínicas presentes na Psicodinâmica do Trabalho (Dejours, 2012) e na Clínica da Atividade (Clot, 2010), assim como as contribuições de autores que investigam, a partir desses referenciais, os transportes terrestres (Cunha \& Lacomblez, 2006; Forzy, 2007; Valot, 2007; Cunha \& Lacomblez, 2008; Vidal-Gomel, Delgoulet \& Geoffroy, 2014). 


\section{Considerações teóricas}

7 A partir da Ergonomia da Atividade, reconhece-se que a atividade de trabalho nunca é somente pura execução do prescrito. Essa descoberta nos introduz a questões que devem ser consideradas quando se investiga um determinado trabalho: de um lado, deve-se conhecer tanto as condições estruturantes e contextuais (a situação específica) em que um trabalho se dá, quanto as pessoas e os recursos (físicos, subjetivos e coletivos) de que dispõem para agir, individual e coletivamente. De outro, deve-se conhecer o que e como se faz, no curso da atividade, diante de problemas (variabilidades, sejam as parcialmente previsíveis, sejam aquelas fruto do acaso) sempre singulares, observando seus efeitos na produção e nos operadores. Nesse sentido, é importante compreender o que é necessário para realizar um bom trabalho, aquele no qual as pessoas podem se reconhecer em atividade (Clot, 2010), bem como serem reconhecidas por suas contribuições, a partir de diferentes formas de julgamento efetuadas, especialmente por seus pares (Dejours, 2012). Nessa dinâmica, não é só a meta estabelecida que se garante, ou que se inviabiliza, mas também a própria saúde (mental) dos trabalhadores.

8 Verifica-se que ao procurar dar conta da tarefa extrapola-se o prescrito em um processo complexo e enigmático. Na produção (material e/ou simbólica), aqueles que trabalham são convocados integralmente, "corpo e mente", individual e coletivamente, pelas variabilidades previsíveis e pelo acaso. Nessa convocação - de si e do coletivo sempre em parte inusitada, os trabalhadores devem agir de modo qualificado e competente, colocando em debate as normas previamente existentes e outras que se fazem necessárias, vis-à-vis as infidelidades e exigências do meio. Nesse debate de normas que se desenvolve em meio a um mundo de valores, tanto o trabalhador individual e coletivo - quanto o próprio meio podem estar se reconfigurando, mesmo que no ínfimo, a partir do processo de renormatização (Schwartz \& Durrive, 2010; Athayde \& Brito, 2011). Nessa perspectiva são desenhados mundos do trabalho sempre em devir, em processo, onde a última palavra nunca é dita e onde se pode até mesmo encontrar reservas de alternativas ao que está dado (Athayde \& Brito, 2011).

De maneira sintética, destacamos alguns pontos fundamentais nessa linhagem: 1) a distância sempre presente entre o que foi prescrito enquanto tarefa e aquilo que se realiza (ou não) no curso da atividade; 2) essa defasagem caracteriza o viver, é universal, não se dá apenas em situação de trabalho; 3) a produção/superação desse hiato é fruto de uma atividade diferente da prevista e é parcialmente enigmática; 4) nessa atividade, o meio, as próprias pessoas e coletivos ali envolvidos se ressingularizam; 5) esse processo se desenvolve em um meio onde circula um mundo de valores, com toda a sua complexidade; 6) é essa atividade que, em alguma medida, viabiliza a obtenção dos produtos/serviços previstos e exigidos pela tarefa; 7) além de produtos-serviços-mercadorias, nessa atividade se produz também subjetividades e coletivos de trabalho; 8) é também por meio dessa atividade que se engendra o complexo processo saúde-doença dos trabalhadores (Falzon, 2007; Clot, 2010; Athayde \& Brito, 2011; Dejours, 2012). Enfim, é com a influência dessa linhagem epistemológica e teórico-metodológica que se desenhou e realizou a investigação ora apresentada. 


\section{Método}

Trata-se de um estudo exploratório transversal, descritivo, de natureza quantiqualitativa, realizado no período de 2006-2007, na cidade de Vitória-Espírito Santo/ Brasil, do qual participaram 189 motoboys, inseridos em diferentes etapas do estudo, que atuavam em diversos setores, como entregadores de documentos, alimentos e medicamentos, em diversas regiões do município. Para traçar o perfil dos trabalhadores e obter informações gerais sobre a profissão, na etapa inicial da pesquisa aplicou-se um questionário semiestruturado junto a este conjunto de trabalhadores (189), por meio de uma amostra de conveniência, contendo questões relativas a dados sociodemográficos, condições organizacionais e físicas do trabalho, efeitos sobre a saúde, natureza das relações contratuais e informações sobre o sindicato e as empresas. Na medida em que na busca realizada não foram encontrados dados oficiais sobre o tamanho da população de motoboys no município em que o estudo ocorrera, a quantidade de trabalhadores entrevistados com o uso do referido questionário restringiu-se aos que foram encontrados durante o período designado para esse fim (15 dias), nos locais já detectados pela equipe de pesquisa. Vale ressaltar que esse questionário foi criado para essa pesquisa e validado em pré-teste. Os dados produzidos por meio desses instrumentos foram submetidos a análises descritivas de frequência, mas não se pretendia que fossem generalizáveis para a população de trabalhadores. Por outro lado, na medida em que esses questionários foram respondidos por quase todos os profissionais que se encontravam presentes nos grupos de motoboys detectados e abordados pela equipe de pesquisa durante essa primeira etapa de investigação, podese considerar seus resultados como retratos relativamente satisfatórios e complementares às informações obtidas nas outras etapas, de cunho qualitativo. Ressalte-se, também, que além de fornecer dados gerais sobre as características pessoais, profissionais e sociais e as condições e organização do trabalho dos motoboys, os resultados dessa etapa foram utilizados como elementos de debate que auxiliaram na condução das conversas entre profissionais de pesquisa e trabalhadores (convocados em seu potencial investigativo), conforme o que propõe a Ergologia, operando um dispositivo de análise que privilegia o ponto de vista da atividade, os "encontros sobre o trabalho" (Schwartz \& Durrive, 2010).

11 Esses "encontros" foram realizados, sobretudo, na região central do município, envolvendo motoboys que utilizavam locais públicos da cidade - praças e becos - como locais de espera pela designação das suas tarefas por parte de chefias e/ou clientes. Esses encontros se desdobraram em momentos de conversas menos estruturadas, sem suporte de temas previamente elencados e sem registros de áudio ou vídeo, ou em encontros mais estruturados, conforme descritos abaixo. A partir deles, o processo, as condições e formas de organização do trabalho e dos coletivos, assim como as próprias atividades de trabalho foram mobilizadas para debate, visando sempre uma análise coletiva do trabalho (sob influência de experimentações há muito validadas, com as iniciadas por Ferreira (1993), e outros, a partir do ponto de vista da atividade. Também contribuíram para os debates, nesses momentos mais ou menos estruturados, as informações produzidas por meio da observação participante, técnica inspirada em uma abordagem etnográfica do trabalho (Sato \& Souza, 2001) e apoiada nos pressupostos ético-epistemológicos da Ergologia (Schwartz \& Durrive, 2010; Athayde \& Brito, 2011). Essa operação desenvolveu-se por nove meses, com visitas semanais a 4 
pontos da cidade - entre os quais, aqueles em que os encontros se realizaram e onde também realizou-se aplicação de questionários -, sendo estes, locais em que os motoboys esperavam os telefonemas para agendamento de serviços.

As informações e conhecimentos produzidos por meio das entrevistas menos estruturadas (que denominamos "conversas") e das observações foram registrados em diários de campo. Estes serviram de suporte para análises, debates e ilustrações de informações geradas em outros momentos mais estruturados. Entre esses momentos, destacam-se as seguintes estratégias:

- entrevistas individuais semiestruturadas e em profundidade realizadas com 13 motoboys e entrevistas coletivas, também semiestruturadas e em profundidade, realizadas em 10 momentos distintos, envolvendo número variado de trabalhadores, dispostos a participar durante seus intervalos de espera. Tais procedimentos objetivaram indagar sobre questões extraídas das observações e das conversas informais, tais como: aspectos ergonômicos do trabalho e suas relações com a saúde; dimensões cognitivas e afetivo-emocionais em relação ao trabalho, à família e ao trânsito; perspectivas profissionais e pessoais em relação ao futuro; dimensões coletivas das atividades; etc.

- debate coletivo ("encontros sobre o trabalho") com foco sobre a profissão, tendo a participação de 50 motoboys, em dia e local fora do trabalho, envolvendo discussão sobre as relações entre saúde, trabalho, aparelho sindical e movimentos de luta política;

- autoconfrontação simples e instruções ao sósia: tendo como foco estrito as atividades de trabalho em situações reais, fez-se uso de outra modalidade de co-análise do trabalho, envolvendo duas técnicas, baseadas no princípio mais geral da confrontação, tradição da Ergonomia da Atividade (Falzon, 2007). A autoconfrontação simples foi realizada por meio de filmagem de atividades de trabalho de 2 motoboys, operada por um especialista em cinematografia que seguiu, durante vários minutos de um dia de trabalho, cada um dos 2 profissionais. $\mathrm{O}$ especialista realizou sua filmagem na garupa de uma motocicleta de um membro da equipe de investigação que seguia o motoboy ao longo de sua jornada. Os resultados obtidos com a filmagem foram exibidos para cada participante, ao qual se seguiram conversas a respeito. A outra técnica, realizada com 1 motoboy, denomina-se instruções ao sósia, técnica criada na Itália por Oddone e seus parceiros do Modelo Operário Italiano de produção de conhecimento e luta pela saúde (Oddone, Re, \& Briante, 1981; Vasconcelos \& Lacomblez, 2005), mas influenciada pelo modo como a Clínica da Atividade a vem operando (Clot, 2010).

13 Como dito, o uso desse conjunto de instrumentos tinha 2 propósitos: gerar materiais linguageiros que alimentariam a análise a ser efetuada pela equipe de pesquisa; e produzir diferentes momentos nas relações dialógicas entre trabalhadores (convocados a exercitarem sua capacidade investigativa sobre seu próprio trabalho) e pesquisadores profissionais, construindo com base no trabalho concreto, situado, de forma coinvestigativa, um quadro do que fazem os motoboys. Daí foi possível fazer emergir questões ainda pouco ou não conhecidas, para o coletivo constituído pelos membros da equipe profissional de investigação e motoboys. Nessas etapas, e a partir dos próprios encontros sobre o trabalho, procurou-se compreender as normas e valores que circulavam, os saberes, e sentidos que os trabalhadores produziam e partilhavam sobre sua profissão, suas relações de trabalho, interesses, enfrentamentos e insatisfações, inclusive os meios de organização sócio-política em torno desta profissão, que entendemos como ainda em gestação. Para eliciar e desenvolver tais reflexões, fez-se uso de diversas estratégias analíticas. Nos debates, a função dos animadores da 
discussão era, entre outras, de reenviar ao coletivo algumas interpretações e análises realizadas a partir das falas dos próprios participantes. Assim, parte das análises foi validada em um processo de coprodução de informações sobre as experiências de trabalho desses profissionais. Por outro lado, as entrevistas individuais e coletivas, bem como as técnicas de instruções ao sósia e de autoconfrontação, foram gravadas e transcritas e seus conteúdos analisados e interpretados, por meio da análise temática (Bardin, 2011), em sua relação ao já citado conjunto teórico de referência. Já os dados dos diários de campo, produzidos a partir dos "encontros" e observações, foram registros que deram suporte aos resultados encontrados nessa triangulação de métodos (observações, questionários, entrevistas, conversas, encontros e debates) e na própria análise geral do que emergia ao longo da pesquisa.

Sendo assim, o que foi gerado no plano compreensivo pela investigação está amparado tanto em dados quantitativos, quanto em materiais discursivos, nos quais, para os presentes objetivos, importa menos a frequência de sua emissão, mas os sentidos que mobilizam. O pressuposto era que as informações geradas através de técnicas quantitativas poderiam articular-se de forma sinérgica ao material tratado qualitativamente permitindo melhor compreender o trabalho desenvolvido por esses profissionais.

15 Para a análise dos materiais emergentes teve-se como base algumas abordagens do campo que vem sendo denominado Clínica do Trabalho (Lhuilier, 2006), especialmente a Psicologia Ergonômica / Ergonomia da Atividade (Guérin, Laville, Daniellou, Duraffourg \& Kerguelen, 2001; Vasconcelos \& Lacomblez, 2005), a Psicodinâmica do Trabalho (Dejours, 2012) e a Clínica da Atividade (Clot, 2010), tendo como orientação geral articuladora a démarche ético-epistemológica da Ergologia. Os princípios éticos de autonomia dos sujeitos e confidencialidade dos resultados foram preservados.

\section{0 ingresso na profissão}

16 Para compreender as características dos trabalhadores e suas relações com as exigências impostas em termos de condições de trabalho (Leplat \& Cuny, 1998), procurou-se conhecer algumas dimensões sociodemográficas do grupo profissional em foco. Dos 189 trabalhadores que responderam ao questionário, todos homens, 74,3\% tinham menos que 30 anos. 0 tempo médio de atuação na profissão foi de 4 anos, sendo que $10,1 \%$ relataram exercer a atividade há mais de 10 anos. Além disso, $84 \%$ dos entrevistados cursaram até o Ensino Médio completo e $78 \%$ dos participantes da investigação residia na periferia da cidade, região em que se encontram, sobretudo os bairros com maior quantidade de famílias com baixo poder econômico de consumo. Os casados representaram $51 \%$ e $54 \%$ com filhos, $26 \%$ deles possuindo outros dependentes. Essas informações são semelhantes às encontradas em outras investigações (Diniz, 2003; Oliveira, 2003; Silva, 2006).

O perfil desses trabalhadores corresponde, socialmente, a uma grande parcela de jovens que não ingressaram na educação universitária, mas que apresentam escolaridade parcialmente acima daquela de brasileiros com idade mais elevada, em condições socioeconômicas semelhantes (Corbucci, Cassiolato, Codes \& Chaves, 2009). Corresponde também ao perfil de trabalhadores que atuam em outros ramos profissionais, tais como os de call centers (Silva \& Mocelin, 2009), com diferenças que revelam aspectos psicossociais importantes na organização, valorização e 
consequências destas formas de trabalhar: predomínio de homens na profissão de motoboys e de mulheres nos call centers. A partir da concepção da presença de uma divisão sexual do trabalho em nossa sociedade (Hirata, 2009), pode-se supor que as percepções sociais sobre o que se supõe atributos masculinos (coragem, virilidade) e femininos (capacidade de relacionamento verbal, empatia), contribuem para conduzir jovens dessas origens socioeconômicas a uma ou outra profissão. Pode-se supor, também, que esses atributos masculinos sejam utilizados como justificativa para a relativa tolerância social aos acidentes entre motoboys, na medida em que se reconhece que é um trabalho perigoso em si, o qual se poderia alterar muito pouco, requerendo atributos masculinos (como a coragem e virilidade) para o exercício dessa profissão. Por outro lado, eles parecem ficar mais tempo na profissão (32,4\% responderam que trabalhavam na profissão há mais de 5 anos e 10,1\% há mais de 10 anos) que as operadoras dos call centers, conforme pesquisa de Silva e Mocelin (2009) que demonstrou que apenas $10,95 \%$ dos trabalhadores estavam na profissão há mais de 24 meses.

Muitos motoboys apresentaram motivos bem "instrumentais" para o ingresso nesta profissão, sobretudo durantes as entrevistas por questionários, onde $32,8 \%$ dos respondentes ressaltaram diferentes vantagens para terem ingressado na profissão: ampla oferta de emprego (formal ou informal) nesse ramo (9,5\% dos respondentes); exigência de menor qualificação e facilidade no trabalho (7,9\%), mas com "bom retorno financeiro" (14,8\%); vantagens da flexibilidade de horários, liberdade de trabalhar sem a presença de uma supervisão ou vigilância contínua do chefe; e, para alguns que atuam no transporte de documentos, as folgas nos fins de semana (5,2\%). Esses dados indicam que o ingresso na profissão pode envolver uma vontade explícita na escolha, sobretudo se somarmos a eles os que afirmaram que escolheram a profissão porque gostavam de andar de moto, nela se realizavam, ou simplesmente porque dela gostavam (12,7\%). Por outro lado, outros discursos, eliciados em conversas menos estruturadas, nos forneceram indícios para compreender alguns motivos menos explícitos que os conduzem à profissão. Trata-se aqui, sobretudo, de justificativas e concepções sobre a ocupação carregadas de simbolismos, mitos e fantasias, tais como: vivência de autonomia parcial em relação à presença de um chefe durante o exercício profissional; sentir-se beneficiado por poder ser remunerado para conduzir um veículo como a motocicleta, simbolicamente atrelada ao apelo pela ousadia, confrontação e liberdade, ao mesmo tempo possibilitando ser reconhecido como pessoa com coragem e virilidade. Nesse aspecto, percebeu-se a presença das relações de gênero, através de um discurso reticente quanto à presença de mulheres na profissão. Dentre os argumentos nesse sentido encontrou-se, por exemplo, um motoboy que argumentava tal exclusão não no plano da (in)competência delas, mas pelo sofrimento que elas passariam quando se acidentassem, já que era consensual que um motoboy inevitavelmente cai algum dia. Enfim, essas concepções mais simbólicas sobre a profissão coadunam tanto com o que se identifica como perfil social dos motoboys - homens jovens, de periferia urbana com escolaridade mediana -, quanto com um ideário de virilidade (e as defesas psíquicas de tipo ideológico) que também foi referido por outros autores que estudaram essa profissão (Neto et al., 2006).

19 Entretanto, contrário ao que se supunha inicialmente, a dimensão dos riscos de acidentes não atuou explícita e conscientemente como principal coadjuvante na decisão de entrar e permanecer na profissão (por exemplo: apenas 2,1\% ressaltam, no questionário, alguma dimensão de risco atrelada ao ingresso na profissão). Talvez 
porque parte da percepção negativa acerca dos riscos seja ao menos parcialmente dissimulada pelos trabalhadores por meio de sistemas coletivos de defesa, especialmente o de tipo ideológico (Dejours, 2012). No caso desse coletivo profissional tal tipo de defesa se revela, por exemplo, na exacerbada valorização da capacidade pessoal de antecipar os movimentos de outros veículos no trânsito, o que permitiria uma condução presumidamente eficaz, ágil e segura (Drumond et al., 2007). De fato, por várias vezes os motoboys afirmavam sua capacidade de "olhar adiante" e discriminar, nos retrovisores dos veículos à frente, a direção do olhar dos seus condutores, permitindo-lhes prever para qual direção iriam, razão pela qual denominamos essa regra como "estratégia do olhar adiante". Em contrapartida, ao menos em um aspecto, os riscos profissionais estariam contribuindo para o processo de tomada de decisão quanto à atração por essa carreira profissional. Segundo Veronese (2004), as decisões que levam o pretendente a optar ou não pela profissão dependem de uma análise realizada pelos candidatos, a partir da qual cada um poderá comparar os benefícios da profissão, os riscos envolvidos, a gravidade de seus possíveis danos e os meios de enfrentá-los. Assim, por meio de avaliações cognitivas e afetivas sobre a dialética risconecessidade-custo-benefício, pode-se entender que o pretendente dimensiona e hierarquiza os riscos produzidos pelo trabalho, identificando os que dependem ou não do seu controle. A partir daí desenvolve meios de gerir esse complexo conjunto de fatores potencialmente produtores de situações de risco, posicionando-se de maneira a poder optar tanto por ingressar (ou não) na profissão, quanto por nela continuar. Esse processo parece influenciado pelas trajetórias de vida e influências socioculturais de cada um.

Porém, não é regra que essa escolha seja tão planejada. Em nossas conversas, muitos deles relataram que ingressaram na profissão tendo-a como atividade complementar a outras ocupações, fato também observado em $6,9 \%$ dos respondentes ao questionário. Sabe-se também que muitos que nela permanecem o fazem por meio de vínculo parcial, sobretudo os que atuam em serviços de entrega de alimento, em período noturno (vantagem percebida como flexibilidade e liberdade que a profissão oferece). Outros alegam que persistem por "falta de opção" - termo recorrente nas entrevistas, conversas e encontros - até surgir outra que seja considerada melhor. De fato, $46,4 \%$ dos trabalhadores que responderam ao questionário afirmaram estar na profissão pela "falta de opção" no mercado de trabalho e pela necessidade de sobrevivência econômica. Dizem que, em seu entendimento, não obteriam remunerações semelhantes em outras atividades, dado igualmente verificado em outras investigações (Diniz, 2003; Oliveira, 2003; Veronese, 2004).

21 Além das ponderações, planejadas ou não, nas decisões de ingresso na profissão, como vimos, outros processos sociais contribuem para levar à referida profissão: origem social, redes de relações pessoais e sociais, intensidade de ligação com a motocicleta, perspectivas e responsabilidades financeiras, assim como experiências em outras ocupações. Tal quadro está coerente com investigações realizadas a partir de outros referenciais teórico-metodológicos que, conforme Greenhaus (2003), apontam a existência de múltiplos fatores nas decisões (ou indecisões) concernentes à carreira profissional, tais como aspectos relativos ao trabalho e às expectativas sobre a vida. Conforme o autor sugere, "carreiras estão mais propensas a serem caracterizadas por respostas espontâneas a mudanças de situação que pela busca de planos prédeterminados e metas" (Greenhaus, 2003, p.532, tradução livre). Essa afirmação problematiza a valorização excessiva que alguns modelos contemporâneos de carreira 
dão à ação individual, sobretudo ao planejamento ativo e antecipado das pessoas, tais como o modelo proteano de carreira ou a craft-career (Bendassolli, 2009).

Destaca-se aqui o papel das redes de relações pessoais e sociais na condução de alguém a essa profissão, já que não é incomum (dado que não passou por tratamento quantitativo) uma pessoa nela iniciar-se por meio de um irmão, vizinho ou conhecido. Pode-se afirmar, contudo, que este não é o caminho inevitavelmente trilhado por todos trabalhadores e que, mesmo quando acionado por tais redes, o ingresso não é necessariamente balizado por concepções claras e exclusivamente conscientes sobre a profissão. Diniz (2003), Oliveira (2003) e Veronese (2004), e com base em suas investigações, também afirmam que não se entra na profissão de motoboy conhecendo totalmente a dimensão dos riscos e benefícios nela envolvidos. Entretanto, essas redes de relações contribuem para aproximar as pessoas ao serviço a ser prestado por meio de duas vias principais: tornando presente, possível e pertinente a alguém atuar em um trabalho que, do contrário, seria apenas mais um entre inúmeros outros que habitam o imaginário social; fornecendo materiais simbólicos e teias de sentido, das quais se pode lançar mão para construir concepções de si a partir desse trabalho. Assim, ao modo como se apresentam profissionalmente como motoboys soma-se a outros sentidos mais frequentemente partilhados socialmente, tais como preconceitos e discriminação, contribuindo para o desenho de um cenário possível de ingresso nessa profissão e para a construção de sentidos sobre a carreira e seu desenvolvimento pessoal a partir dela.

Enfim, múltiplos aspectos contribuem para que alguém se torne motoboy e o modo como o faz:

- as características deste trabalho e suas vantagens, tais como o uso da moto durante a profissão, a percepção de certa autonomia no planejamento do trabalho, certa informalidade (tanto no aspecto jurídico quanto na baixa exigência quanto a um modelo de comportamento e de vestimentas a se utilizar), remuneração considerada acima das possibilidades relativas à qualificação profissional requerida;

- as condições de vida das pessoas e sua relação com as possibilidades dessa profissão, tais como o desemprego, a falta de qualificação profissional, a idade avançada para reingressar no mercado de trabalho quando demitido;

- a rede de relações pessoais e sociais.

\subsection{Deixando a profissão ou nela permanecendo}

\subsubsection{Abandono}

Entre os entrevistados, o tempo médio de permanência nesta atividade profissional era de quatro anos, sendo que $21,7 \%$ deles estavam há um ano ou menos na profissão, corroborando dados encontrados em investigação realizada na cidade de Londrina estado do Paraná, onde $26 \%$ dos entrevistados estavam nesta ocupação há menos de um ano (Silva, 2006; Soares et al., 2011). Esses dados são semelhantes aos encontrados nas cidades de Belo Horizonte - estado de Minas Gerais (Diniz, 2003) e de Salvador - estado da Bahia (Oliveira, 2003). Esses autores, bem como os trabalhadores que entrevistamos, informam que esse contínuo ingresso de novatos na profissão relaciona-se à alta rotatividade nesta ocupação.

Oliveira (2003) sugere que este fenômeno relaciona-se às condições socioeconômicas dos candidatos, ao limite de possibilidades de crescimento e desenvolvimento profissional, ao esgotamento da tolerância às condições de trabalho, ou ao fato de os 
motoboys pretenderem, com a demissão, fazer uso do seguro-desemprego. No Brasil, o seguro-desemprego, de responsabilidade do Ministério da Previdência Social (e que atualmente está sendo objeto de duras modificações), era uma modalidade de assistência financeira temporária ao trabalhador contribuinte do sistema e que tenha sido desempregado sem justa causa e sem recolocação imediata no mercado. Ele poderia durar por até cinco meses, a depender da quantidade de meses trabalhados em um período de 36 meses a contar a partir da data do desligamento profissional. Ainda para (Oliveira, 2003), tão logo apareçam melhores opções, os motoboys deixam a profissão para ingressar em outras, sugerindo que, para muitos deles, trata-se de um emprego-trampolim, conforme Silva e Mocelin (2009): "postos de trabalho temporariamente ocupados pelos trabalhadores, mas que não são atrativos profissionalmente, sendo descartados quando o trabalhador encontra uma melhor oportunidade ou concluem seus estudos, sua formação técnica ou sua graduação". Pode-se relacionar esse movimento planejado de uso e descartabilidade de profissões, sugerido por esses autores, como condizentes com modelos de carreira identificados como emblemáticos dos modos de vínculo de trabalho e de desenvolvimento profissional na contemporaneidade (Greenhaus, 2003; Baruch \& Bozionelos, 2010).

Entretanto, considerando-se o que aponta Greenhaus (2003) e Bendassolli (2009), compreende-se que os movimentos de ingresso, permanência e abandono de uma ou de várias carreiras, ao longo da vida de alguém, não dependem somente - ou nem tanto quanto sugerem alguns (Baruch \& Bozionelos, 2010) - das suas competências, expectativas e intenções. Outras dinâmicas da vida, não tão planejadas, também interferem neste processo, o que parece atestar contra os postulados centrais dos modelos de carreira contemporâneos. Estes, muito frequentemente, preconizam como sinônimo de sucesso profissional a manutenção de alguns traços de personalidade e de supostas boas escolhas deles decorrentes. Aliás, vale mencionar que esses modelos foram geralmente construídos de modo a ignorar a experiência de populações com menor escolaridade, em profissões não tradicionais ou de nível gerencial, e com outros referenciais subjetivos de sucesso profissional (Greenhaus, 2003; Bendassolli, 2009). Finalmente, não se pode ignorar que esses modelos produzem efeitos muitas vezes indesejáveis, tais como aumento de transtornos mentais leves, ansiedade e "corrosão de caráter" e "de tradições" (Sennett, 2012).

Seja como for, a percepção de relativa provisoriedade da profissão e mudança constante de pares produzem efeitos nos modos e estratégias de solucionar os constrangimentos do trabalho real (Falzon, 2007), na medida em que dificultam a possibilidade de acessar a rede de solidariedade (Diniz, 2003) constituída ao longo do tempo e que pressupõe, em sua base, confiança e experiências em comum (Moraes, 2008; Dejours, 2012). Ademais, o contínuo ingresso de novos trabalhadores interfere, também, na barganha salarial, na partilha de saberes e competências profissionais e, consequentemente, talvez contribua para o aumento do número de acidentes de trabalho.

\subsubsection{Permanência e futuro}

28 Apesar da alta frequência de abandono em relação à profissão, 32,4\% dos motoboys exerciam essa atividade há mais de cinco anos; um deles relatou que está na profissão há vinte e cinco anos. Assim como o abandono, o tempo de permanência na profissão também produz efeitos significativos no modo como esses profissionais atuam, tais como a partilha de conhecimentos, saberes de prudência (Cru, 1987) e valores, bem 
como contribui para a produção de subjetividade por meio do coletivo de trabalho, aspectos também constatados por outros (Diniz, 2003; Oliveira, 2003; Veronese, 2004; Silva, 2006; Grisci et al., 2007; Moraes, 2008; Soares et al., 2011).

Nas entrevistas, conversas e encontros sobre o trabalho, foram citadas várias razões para a permanência na profissão, muitas delas semelhantes às respostas dadas nos questionários, que justificavam o ingresso na profissão. Verifica-se assim, que além das vantagens já percebidas durante o ingresso, outras se concretizam ou se intensificam com a experiência profissional: aumento da empregabilidade; adaptação às exigências físicas e mentais para execução do trabalho que, aos olhos de muitos motoboys, são consideradas menores que em outras profissões; percepção de relativa autonomia e controle sobre a organização do trabalho; vivência de prazer de trabalhar conduzindo motos; possibilidade de ter mais de um emprego; distância física em relação à hierarquia e ao patrão; vivência de liberdade ao não ficar toda a jornada em escritórios fechados, além de poder se vestir informalmente e se comportar de maneira mais descontraída. Essas vantagens sedimentam as intenções de permanência na função, contribuindo para o surgimento de novas expectativas quanto ao futuro profissional e sentimentos de pertença.

Há pelo menos duas grandes perspectivas, não necessariamente excludentes entre si, de manter-se na profissão e relacionar-se com o futuro a partir dela. Alguns declararam: “ permaneço porque não vejo nada melhor em vista, por enquanto, entendeu?"; "como eu disse pra você, é uma profissão que você levanta uma grana com muita facilidade entendeu, mas não é pra minha vida inteira, é coisa temporária". Para estes, a principal vantagem do trabalho dos motoboys é que ele viabilizaria, para quem vive nas condições socioeconômicas mais precarizadas, criar possibilidades de escolha. Ou seja, essa profissão permitiria gerar "novas opções" para trabalhadores que anteriormente a exerciam por "falta de opção". Assim, se o ingresso se dá por "falta de opção", a permanência, não. Um motoboy relatou que nela ingressara a partir de um convite do patrão da padaria em que trabalhava como ajudante de vendas, exemplificando esse cenário. Diz ter aceitado o convite para assumir o cargo na própria padaria e, a partir desta experiência, conseguiu outro emprego como motoboy em uma loja de autopeças, onde havia possibilidade de ascensão, melhores salários e desgaste profissional percebido como menor. Nesta loja, o trabalhador executava também tarefas da função de estoquista, o que abriu a possibilidade de, em poucos anos, exercer a função de vendedor com ganhos salariais mais significativos.

31 Trata-se aqui da construção de uma percepção de que essa profissão, ao lado de garantir ofertas contínuas de emprego, permitiria aos trabalhadores ampliar seus contatos profissionais, aumentando suas possibilidades de escolha e desenvolvimento neste âmbito, relativamente intangíveis antes do ingresso nessa profissão. Alguns autores sugerem que essa percepção, por eles denominada empregabilidade, atua também como fator moderador na satisfação com o trabalho (Cesário, Gestoso \& Peregrín, 2012). Este movimento tem-se dado em um processo construído a partir de sonhos, desencantos e aprendizagens, tornando possível, a partir dessa experiência, outras possibilidades de vida, de empregabilidade, de socialização.

Enfim, a partir do ingresso do trabalhador como motoboy, iniciar-se-ia a construção de algo próximo daquilo que se pode denominar uma "carreira". Esta não deveria ser apreendida a partir dos modelos tradicionais verticalizados, aproximando-se mais dos modelos mais recentes, tais como o proteano, sem fronteira ou carreira-artesã (craft- 
career), (Bendassolli, 2009; Baruch \& Bozionelos, 2010). Isso porque nestes modelos verifica-se uma busca consciente de trabalhadores por oportunidades profissionais, independente dos trajetos verticais desenhados pelas organizações e nem sempre vinculados a uma mesma profissão. Contudo, não se pode afirmar que esse planejamento antecipado emerge sempre antes da profissão - o termo "falta de opção" ilustra isso bem - mas como um dos efeitos desta na vida dos trabalhadores, impedindo parcialmente o seu desenvolvimento profissional. Além disso, os modelos recentes de carreira parecem refletir processos sociais distintos: referem-se mais frequentemente a jovens com alta escolaridade que, partilhando valores que ressaltam o individualismo e o empreendedorismo, constroem seus sonhos de sucesso independentemente de vínculos empregatícios (Bendassolli, 2009). No caso em análise, trata-se usualmente de jovens menos escolarizados, que aprendem a "se virar" desenvolvendo habilidades mais vantajosas "para se viver", sem seguir, necessariamente, uma trilha. Neste sentido, talvez seja mais pertinente compreender aquilo que se denominaria de "carreira dos motoboys" como "desenvolvimento psicológico de si" por meio da atividade de trabalho (Clot, 2010). Em ambos os processos sociais descritos, o vínculo profissional não se dá com uma única organização ou ofício em que se permanecerá por toda vida, mas os pressupostos, mecanismos e resultados dos desenvolvimentos profissionais de cada grupo são diferentes. Assim, mais que um emprego-trampolim, que descreve as experiências de trabalho temporário dos mais escolarizados, poder-se-ia denominar o trabalho dos motoboys como um "emprego-gerador", na medida em que nele se entra sem perspectivas e dele se sai com uma ou mais possibilidades previamente insuspeitadas.

Identificou-se, ainda, outra perspectiva de futuro construída a partir da profissão. A respeito da permanência na profissão, ouvimos em entrevistas, conversas e encontros sobre o trabalho, falas como a que segue: "como eu gosto da profissão, eu pretendo ficar pelo resto da vida". Diferente da produção linguageira que valoriza a permanência nessa função, essa construção discursiva parece mobilizada por outros efeitos da experiência profissional. Mais que um emprego-gerador, para alguns motoboys essa profissão permite a produção de referenciais subjetivos de reconhecimento de si nessa atividade (Clot, 2010). Destarte, em meio às vantagens, desafios, superações, aprendizagens e desenvolvimentos que a profissão possibilita, os materiais produzidos na investigação levaram à pista de que os motoboys vão observando, em atividade, possibilidades reais de desenvolvimento pessoal e profissional. Em contrapartida, além do desenvolvimento pessoal, ao ingressar na profissão pode-se observar o trabalho temporário assumindo, aos poucos, conotação de profissão, forjando-se nesse processo um profissional, e, nesse mesmo movimento, o curso de engendramento de uma profissão.

\subsection{A produção de um profissional e de uma profissão}

34 Mesmo que muitos motoboys tenham afirmado que inicialmente não pretendiam exercer a função por muito tempo, constatou-se que a permanência de alguns tem sido suficiente para o desenvolvimento daquilo que, a partir da Sociologia das Profissões, considera-se "profissão" (Bendassolli, 2009): fenômeno individual, social e institucional, representando formas sociohistóricas de divisão e organização do trabalho, por meio das quais, pessoalmente, se encontra referências simbólicas para construção de si mesmo e de realização em relação ao trabalho. Este autor ressalta que, por meio dessas formações sociais institucionalizadas, mobilizam-se coletivos em defesa de seus 
interesses e de seu reconhecimento, pelo Estado, como representantes legítimos de saberes e práticas exclusivas que os autorizam a exercer a profissão. É nesse sentido que se verificou que a permanência de motoboys exercendo suas atividades vem propiciando a invenção de "modos de ser motoboy" (Grisci et al., 2007), assim contribuindo para a produção de meios de se compreender, atuar e transformar - a si mesmo, os colegas, as condições e as exigências do trabalho, bem como as relações entre o trabalho e sua vida pessoal, social, institucional e política. Estes "modos de ser motoboy" são consequência da atividade humana realizada envolvendo a dialética entre normas antecedentes e renormatizações (Schwartz \& Durrive, 2010), que articulam a materialização de um mundo subjetivo, relacional, cultural, social e político. Assim, para além da regulamentação da profissão (Lei $\mathrm{n}^{\circ}$ 12.009, de 29 de julho de 2009), esta possível nova profissão vem encontrando referências concretas, mesmo que imateriais, entre trabalhadores. Percebeu-se a presença, em nossa investigação, do início de um gênero profissional (Clot, 2010; 2014), desenvolvendo-se na interseção entre produzir-se enquanto profissional e produzir coletivamente uma profissão por meio do cotidiano de trabalho.

Um breve episódio permite ilustrar como isso vem se dando entre estes trabalhadores. Durante uma conversa usando a técnica de autoconfrontação, mediada pelo uso de imagens, em que um motoboy se vê em atividade, ele, com sorriso no rosto, diz:
eu gosto de trabalhar de motoboy. [...] gosto da sensação de liberdade. A sensação de liberdade é incrível [...] me sinto que nem uma criança às vezes, entende? Sem ninguém para ficar me perturbando. Apesar que o pessoal liga pra caramba, o telefone toca o tempo todo, querendo saber o que está acontecendo, se está tudo certo, e tal. Mas, pô, a sensação compensa, cara. Não é um lugar, um ambiente fechado, que você trabalha naquele ambiente, naquela pressão e tal. É uma pressão, mas, você está respirando o ar, está do lado de fora, sentindo o clima, sentindo o sol, o vento... Isso é bom pra caramba. A gente vê coisas, pessoas.

Relatos como esse não foram exceção. A sensação de atuar como motoboy pode ser compreendida por meio da referência à infância (Dejours mobiliza o conceito de ressonância simbólica), reportada aqui como um período de descoberta, de experimentação e de um aprendizado que se dá especialmente por meio da atividade lúdica. Sabe-se que a capacidade de fantasiar das crianças tende a torná-las mais hábeis em se distanciar temporariamente do mundo real, parecendo a um observador, que ela consegue viver mais independente, em um mundo cognitivo só dela, um mundo de criações, de experimentações. No caso do adulto, limites maiores vão se impondo a essa capacidade. Conforme a narrativa deste motoboy, a sensação de ser livre, de "curtir um vento", uma brisa, é reinterpretada como um simples, mas fundamental prazer de ser. No momento de pilotar a moto, a vivência relatada é a de como se o mundo fosse seu, cheio de diversão, possibilidades, sonhos e fantasias. Não obstante uma liberdade fugaz, pois a pressão do trabalho é contínua, narra encontrar ali um prazer incomensurável, que lhe permite dizer, sorrindo: "eu gosto de ser motoboy".

Ao remontar a esse sentimento, o motoboy pode estar também se referindo a outro aspecto: sua destreza na condução da moto e na resolução das demandas do trabalho é de tal ordem que lhe é possível sentir-se livre, mesmo em meio às extremas exigências espaço-temporais cotidianas. Talvez por perceber-se em simbiose com a motocicleta e com a atividade, descobrindo ou inventando aí espaços de fantasia, liberdade, prazer. 0 
trabalho é considerado intenso, mas ele afirma dar conta, a ponto de poder inventar e, em certa medida, ter prazer com suas atividades. Ao "dominar" o trabalho, esse se torna um campo em que o indivíduo passa a se produzir como pessoa, a se desenvolver. Momento em que ele próprio se testa, se controla, se produz e fantasia, para exercer mais criativa e astuciosamente sua autonomia e liberdade, em meio às responsabilidades que se assume ao trabalhar. Trata-se de uma experiência cognitiva, mas também corporal e afetiva, que não seria possível se ele estivesse focado exclusivamente na remuneração. A função psicológica do trabalho (Clot, 2010), aqui se revela: o motoboy parece conseguir se ultrapassar em suas condições prévias (as demandas, as responsabilidade), "saindo de si" (sentindo-se criança, com a brisa no rosto) e se desenvolvendo, ao dar conta de uma realidade complexa (telefone tocando, inserções de controle) e, no fim, emergindo o sentimento de realização que lhe remete aos prazeres da infância, mas já agora como adulto que trabalha, incorporando o lúdico. Sair de si revela-se como um inventar-se, experimentar-se, quiçá podendo ousar a expressão "experinventar-se", enfim, um processo que o desenvolve, "faz crescer".

Visões negativas dos motoboys em relação ao próprio trabalho, ressaltadas por alguns autores (Oliveira, 2003) e continuamente veiculadas pelos meios de comunicação no Brasil, são apenas uma parte, talvez menos importante, dos discursos e vivências dos motoboys acerca de sua profissão. Fatores vividos como negativos foram relatados: por exemplo, durante as oficinas/encontros sobre o trabalho realizadas com 50 trabalhadores, a tônica do debate esteve nas queixas com relação às condições precárias de trabalho, nos preconceitos que percebem por parte de condutores de outros veículos, nos riscos da profissão, na falta de organização de um coletivo profissional, na dificuldade em poder confiar totalmente em colegas, no comportamento de condutores profissionais de outros veículos em relação a eles (sobretudo por meio de "fechadas", etc.). Essas foram razões apresentadas que contribuiriam para que muitos abandonem a profissão. Porém, conforme o relato de um trabalhador em processo de autoconfrontação nos permite entrever que a despeito de todas as críticas, a vivência relatada de liberdade propiciada pela moto e pela destreza de dominar-se enquanto piloto e de inventar-se com uma profissão parece compensar, parcialmente, essas dificuldades, conotando de positividade o sentido de ser motoboy.

Tal positividade ecoa também em seu relato acerca da relevância dos serviços que prestam. Diniz (2003) ressalta o esforço destes trabalhadores no desenvolvimento de estratégias (ou modos operatórios), capazes de tornar seu trabalho mais produtivo, aumentando a satisfação dos clientes, ao mesmo tempo em que se beneficiam com o aumento dos ganhos financeiros, por exemplo. Essas estratégias podem envolver mais ou menos riscos, mas também a produção de saberes que lhes permitem aumentar a ousadia no modo de condução, mantendo uma margem de segurança que consideram suficientes para realizar os serviços de maneira satisfatória. Ou seja, a precariedade das relações de trabalho a que estão submetidos não inviabiliza seu profundo envolvimento nas atividades, propiciando tanto desenvolvimento subjetivo quanto a construção de saberes coletivos que permitem aumento de eficiência e segurança na realização dessas atividades (Diniz, 2003).

Aliás, essa psicodinâmica prazer-sofrimento (Dejours, 2012) aponta, em grande medida, para o processo de construção de um sentimento de coletividade (Neto et al., 2006) que contribui para a produção de um gênero profissional (Clot, 2010), a saber: a partilha de saberes e sentidos que auxiliam, instrumentalmente, a cada um dos trabalhadores do 
coletivo a resolver seus problemas sem precisar "inventar a roda". Os materiais de que dispomos nos permite colocar a pista de que esse coletivo encontra-se em plena construção, seja com base nas partilhas das experiências pessoais-profissionais, seja nos bate-papos informais entre trabalhadores enquanto aguardam nas praças, calçadas ou em frente às lojas pela designação de novas tarefas. Ali, e em vários outros momentos do cotidiano dos motoboys, esse coletivo, mesmo que ainda incipiente, fornece saberes e também compõe/impõe "regras de ofício" que, com o passar do tempo, se tornam realmente uma "arte de viver" (Cru, 1987). Uma dessas regras, por exemplo, evidenciou-se ao fazer uso da técnica de autoconfrontação, quando um trabalhador nos pareceu buscar esclarecer, de maneira enfática, que um motoboy nunca retarda a tarefa de entrega do colega. Essa poderia se configurar como uma regra de ouro da profissão que está sendo constituída. Ademais, além da dimensão estritamente técnica de pilotagem, observarmos que também os gestos e trejeitos dos motoboys, seus modos de falar, comportar-se, raciocinar, de sentir e de viver a vida se afetam e se produzem por essa arte de viver. As vestimentas, os tipos de gozação feitos aos colegas, as modalidades de passatempo, são parcialmente partilhados. Mesmo que a vontade ou a recusa em se tornar motoboy não esteja necessária e/ou diretamente relacionada à satisfação engendrada pelas atividades que compõem a profissão, o prazer que ali se desenvolve cumpre um papel importante na produção de processos subjetivos que exercem importante função psicológica na sua vida e saúde. Ao mesmo tempo, verificase também aí o papel do coletivo de trabalho em operação, já que a identificação com essa profissão somente é possível caso os coletivos que a constituem disponibilizem materiais simbólicos necessários para construção desse vínculo singular entre um trabalhador e suas atividades. Sem um gênero profissional, mesmo que neste caso em constituição, é impossível uma estilização (modo singular de atualizar o gênero na experiência e constrangimentos da atividade cotidiana), e vice-versa (Clot, 2010). Em outras palavras, em meio a um coletivo, partilhando um gênero profissional em formação, esses trabalhadores parecem estar conseguindo inventar um modo de ser trabalhador que lhes permite dar um destino de prazer aos sofrimentos experimentados (passando ao largo da via patogênica), fruir a/na profissão e a si mesmo, por meio dela. A pista que a investigação parece sustentar é a de que produção de um motoboy envolve, o engendramento de um coletivo profissional que permite apreender e reinventar os meios de trabalho, renormatizando as formas de realizar as tarefas a partir de uma gestão de si e das atividades, onde cada trabalhador é mais que um reflexo passivo das imposições e dificuldades da profissão (Schwartz \& Durrive, 2010).

41 Indo além, esse terreno em que se pode construir a si mesmo é enlaçado em modos de organização e divisão dos fazeres e saberes que contemplam princípios socioinstitucionais da profissão e que, em lutas políticas, barganham reconhecimento social que os autoriza a serem agentes sociais e políticos. À diferença de certa tradição teórica da Psicologia do Trabalho e Organizacional que privilegia a compreensão do comportamento individual diante de uma carreira, ou condição social (o mercado) previamente dado (Greenhaus, 2003; Baruch \& Bozionelos, 2010), valorizou-se nesta investigação, a partir de outros referenciais teóricos, o engendramento daquilo que se poderia chamar de "carreira", ao menos entre os motoboys, como produto e produtor concomitante de profissionais e de profissão. profissional (Bendassolli, 2009), verificou entre os entrevistados uma grande 
insatisfação relativamente à atuação do Sindicato (quase $80 \%$ dos respondentes do questionário). Ademais, os trabalhadores relataram descontentamento no tocante à sua desunião enquanto grupo profissional, minimizando a solidariedade evidenciada em matérias jornalísticas veiculadas frequentemente durante o período em que a investigação ocorrera. Este quadro sugere que o movimento de produção de coletivos e de referenciais do gênero profissional que permitem a estilização pessoal (Clot, 2010) ainda encontra dificuldades para sua consolidação no que tange à produção de uma profissão institucionalizada. Entretanto, durante e após o período da investigação, vários movimentos sociais de motoboys começaram a se deflagrar na cidade (Proscholdt, Gaspararini, \& Lacerda, 2006; Folha Vitória, 2009). Esses episódios podem ser compreendidos como outros indícios da produção coletiva, mesmo que inicial e relativamente frágil, de um sentimento de profissão que vincula, a um só tempo, as atividades de trabalho, o desenvolvimento de si, a construção de coletivos de trabalho e sua institucionalização. Vale verificar, em investigações futuras, como esse movimento em curso vem se apresentando atualmente e seu papel (e limites) no que tange à produção das relações entre saúde-doença-acidente.

\section{Conclusões: desafios e possibilidades para políticas públicas neste campo}

Dos resultados desta investigação, pode-se apreender algumas concepções dos motoboys acerca de sua profissão. De um lado, eles percebem aspectos negativos que se coadunam com o preconceito social existente: trabalho desvalorizado/ remuneração baixa/ profissionais desqualificados/ trabalho precarizado/ abandono de profissão/ acidentes/ desmobilização coletiva/ desinteresse pela profissão/ desvalorização social e financeira/ etc. Por outro lado, verifica-se que os riscos de acidentes não são tão fundamentais no processo de ingresso e permanência na profissão, como inicialmente se supunha. Verificou-se um esforço incessante dos trabalhadores para apreender positivamente suas experiências, já que esta ocupação oferece vantagens que levam muitos a investir em seu desenvolvimento profissional a partir, ou por meio dela. Detectou-se também nesse movimento a construção coletiva de um ofício - e de um gênero profissional - que, embora ainda incipiente, sinaliza, por exemplo, a busca de institucionalização profissional, algo que se pode considerar mais importante que a própria regulamentação jurídica da profissão. Em se mantendo o quadro atual de relevância desta ocupação na dinâmica econômica (dada sua contribuição em termos de mobilidade urbana), é possível esperar que os movimentos sociais desses trabalhadores tomem maior consistência e se apresentem mais organizados ao longo do tempo.

Observou-se, porém, que os modos de envolvimento com essa trajetória profissional não são homogêneos, produzindo efeitos distintos: fragilização do coletivo, quando se a vive transitoriamente, produção de empregabilidade, de um profissional e de uma profissão, quando se a vive mais permanentemente. Talvez esta diversidade de trajetórias seja um dos fatores que dificultam a consolidação social da profissão, contribuindo para sua relativa vulnerabilidade nas negociações e lutas políticas para o desenvolvimento de sistemas de proteção - individuais, coletivos e sociais - contra acidentes de trabalho e compensação financeira, quando de sua ocorrência. Isso porque a diversidade de expectativas e relações com suas atividades fragiliza a potência desse coletivo no fornecimento de meios de proteção (saberes e estratégias de defesa) às 
vulnerabilidades coletivas e individuais, ressaltadas por um instrumento de trabalho, a motocicleta, mais vulnerável às morbimortalidades relacionadas aos acidentes.

Entende-se que a consolidação desse coletivo é uma exigência atual e um dos desafios mais importantes a serem enfrentados por parte dos órgãos públicos que têm como tarefa instituir e desenvolver políticas de promoção da saúde e da qualidade de vida no trabalho para esses profissionais. Os meios para essa intervenção deverão passar, conforme os pressupostos ético-epistemológicos e teóricos que guiaram a presente investigação, pelo envolvimento coletivo de trabalhadores e investigadores em uma análise que propicia aumentar a potência de agir dos trabalhadores (Clot, 2010), ao mesmo tempo em que permite o desenvolvimento conceitual dos saberes disciplinares pertinentes à questão (Schwartz \& Durrive, 2010).

\section{BIBLIOGRAPHY}

Amorim, C. R., Araujo, E. M., Araújo, T. M., \& Oliveira, N. F. (2012). Acidentes de trabalho com mototaxistas. Revista Brasileira de Epidemiologia, 15, 1, 25-37.

Athayde, M., \& Brito, J. (2011). Ergologia e clínica do trabalho. In P. F. Bendassolli \& L. A. P. Soboll (Eds.), Clínicas do trabalho (pp. 258-281). São Paulo: Atlas.

Bacchieri, G., \& Barros, A. J. D. (2011). Acidentes de trânsito no Brasil de 1998 a 2010: muitas mudanças e poucos resultados. Revista de Saúde Pública, 45, 5, 949-963.

Bardin, L. (2011). Análise de conteúdo. São Paulo: Edições 70.

Baruch, Y., \& Bozionelos, N. (2010). Career Issues. In S. Zedeck (Ed.), APA Handbook of Industrial and Organizational Psychology, vol. 2 (pp. 67-113). Washington DC: American Psychological Association.

Bauman, Z. (2001). Modernidade líquida. Rio de Janeiro: Jorge Zahar Ed.

Bendassolli, P. F. (2009). Recomposição da relação sujeito-trabalho nos modelos emergentes de carreira. Revista de Administração de Empresas, 49, 4, 387-400.

Cesário, F. S., Gestoso, C. G., \& Peregrín, F. M. M. (2012). Contrato de trabajo, compromiso y satisfacción: Moderación de la empleabilidad. Revista de Administração de Empresas, 52, 3, 345-359.

Clot, Y. (2010). Poder de agir. Belo Horizonte: FabreFactum.

Clot, Y. (2014). Géneros e estilos profissionais. Laboreal, 10, 1, 95-97.

Cocco, G. (2000). Trabalho e cidadania: produção e direitos na era da globalização. São Paulo: Cortez.

Corbucci, P. R., Cassiolato, M. M., Codes, A. L., \& Chaves, J. V. (2009). Situação educacional dos jovens brasileiros. In J. A. Castro, L. M. C. Aquino \& C. C. Andrade (Eds.), Juventude e políticas sociais no Brasil (pp. 89-108). Brasília: IPEA.

Cru, D. (1987). Les Règles du Métier. In C. Dejours (Ed.), Plaisir et souffrance dans le travail (pp. 29-50). Paris: AOCIP. 
Cunha, L., \& Lacomblez, M. (2006). Mudanças no sector dos transportes em Portugal: que caminhos para a actividade de serviço público e para a preservação do interesse geral? Laboreal, 2, 2, 26-37.

Cunha, L., \& Lacomblez, M. (2008). A influência do traçado de mobilidade na noção de território e nas oportunidades de desenvolvimento local. Laboreal, 4, 1, 56-67.

Dejours, C. (2012). Trabalho vivo (Vol. 1 e 2). Brasília: Paralelo 15.

Diniz, E. P. H. (2003). As condições acidentogênicas e as estratégias de regulação dos motociclistas profissionais: entre as exigências de tempo e os constrangimentos do espaço. Dissertação de Mestrado em Engenharia de Produção, Universidade Federal de Minas Gerais, Belo Horizonte.

Drumond, T., Rohr, R., Pereira, F., Ferraz, M., Monteiro, F., \& Oliveira, F. (2007). Estratégias de defesa em constituição: entre a virilidade e a solidariedade. In C. Zanotelli, E. C. Raizer \& V. Valadão (Eds.), Violência e contemporaneidade: dimensões das pesquisas e impactos sociais (pp. 189-205). Vitória: Grafita Gráfica e Editora.

Durrive, L., \& Schwartz, Y. (2008). Glossário da ergologia. Laboreal, 4, 1, 23-28.

Falzon, P. (Ed.). (2007). Ergonomia. São Paulo: Edgar Blucher.

Ferreira, L. L. (1993). A análise coletiva do trabalho. Revista Brasileira de Saúde Ocupacional, 78, 21, 7-19.

Folha Vitória, R. (2009). Protesto de motoboys para Segunda Ponte e congestionamento chega a 4 $\mathrm{km}$. Retirado em abril, 8, 2013, de: http://www.folhavitoria.com.br/site/ ?target= noticia\&cid $=8 \& c h=47 c 4$ ed58a4ea97e 7 a543325df29ed 8 bf $\&$ nid $=109269$

Forzy, J.-F. (2007). Condução de automóveis e concepção ergonômica. In P. Falzon (Ed.), Ergonomia (pp. 557-571). São Paulo: Blucher.

Greenhaus, J. H. (2003). Career Dynamics. In W. C. Borman, D. R. Ilgen \& R. J. Klimoski (Eds.), Handbook of psychology (Vol 12): Industrialand Organizational Psychology (pp. 519-540). New Jersey: John Wiley \& Sons.

Grisci, C. L. I., Scalco, P. D., \& Janovik, M. S. (2007). Modos de trabalhar e de ser de motoboys: a vivência espaço-temporal contemporânea. Psicologia: ciência e profissão, 27, 3, 446-461.

Guérin, F., Laville, A., Daniellou, F., Duraffourg, J., \& Kerguelen, A. (2001). Compreender o trabalho para transformá-lo: a prática da ergonomia. São Paulo: Edgar Blücher.

Hardt, M., \& Negri, A. (2001). Império. Rio de Janeiro: Record.

Harvey, D. (1992). Condição pós-moderna. São Paulo: Loyola.

Hirata, H. (2009). A precarização e a divisão internacional e sexual do trabalho. Sociologias, 21, $24-41$.

Kieling, R. R., Szobot, C. M., Matte, B., Coelho, R. S., Kieling, C., Pechansky, F., \& Rohde, L. A. (2011). Mental disorders and delivery motorcycle drivers (motoboys): a dangerous association. Eur Psychiatry, 26, 1, 23-27.

Kumar, K. (1997). Da sociedade pós-industrial à pós-moderna: novas teorias sobre o mundo contemporâneo. Rio de Janeiro: Jorge Zahar Ed.

Lei no 12.009, de 29 de julho de 2009, Diário Oficial da União, 30/07/2009.

Leplat, J., \& Cuny, X. (1998). Las condiciones de trabajo. In J. J. Castillo \& J. VIllena (Eds.), Ergonomia: Conceitos e Métodos (pp. 109-123). Madrid: Complutense. 
Lhuilier, D. (2006). Cliniques du travail. Toulouse: Érès.

Luna, J. P., \& Oliveira, R. V. (2011). A nova reprodução do trabalho precário e os mototaxistas de Campina Grande. Revista Latinoamericana de Estudos do Trabalho, 16, 25, 91-119.

Moraes, T. D. (2008). Coletivo de trabalho e atividade dos motoboys': gênero profissional, saberes operatórios e riscos da atividade de trabalho. Tese de Doutorado em Psicologia Social, Universidade do Estado do Rio de Janeiro, Rio de Janeiro.

Neto, A. S., Mutaf, J., \& Avlasevicius, S. (2006). Pelo espelho retrovisor: motoboys em trânsito. Revista do Núcleo de Antropologia Urbana da USP. Retirado em novembro, 10, 2006 de http://www.na-u.org/motoboys1.htm.

Oddone, I., Re, A., \& Briante, G. (1981). Redécouvrir l'expérience ouvrière. Paris: Messidor.

Oliveira, G. C. (2003). Trabalho, vitimização e criminalização no cotidiano de motoboys de Salvador. Dissertação de Mestrado em Saúde Coletiva, Universidade Federal da Bahia, Salvador.

Paes-Machado, E., \& Riccio-Oliveira, M. A. (2009). O jogo de esconde-esconde: trabalho perigoso e ação social defensiva entre motoboys de Salvador. Revista Brasileira de Ciências Sociais, 24, 91-106.

Proscholdt, E., Gaspararini, R., \& Lacerda, R. (2006). Novo protesto de motoboys, A Tribuna, de 26 de maio.

Sato, L., \& Souza, M. P. R. (2001). Contribuindo para desvelar a complexidade do cotidiano através da pesquisa etnográfica em psicologia. Psicologia USP, 12, 2, 29-47.

Schwartz, Y., \& Durrive, L. (Eds.). (2010). Trabalho e ergologia: conversas sobre a atividade humana. Niterói: Eduff.

Sennett, R. (2012). A corrosão do caráter: as conseqüências pessoais do trabalho no novo capitalismo (17 ed.). Rio de Janeiro: Record.

Silva, D. W. (2006). Atuação profissional de motoboys e fatores associados à ocorrência de acidentes de trânsito em Londrina, PR. Dissertação de Mestrado em Saúde Coletiva, Universidade Estadual de Londrina, Londrina.

Silva, D. W., Soares, D. A., \& Andrade, S. M. (2008). Atuação profissional de motoboys e fatores associados à ocorrência de acidentes de trânsito em Londrina-PR. Epidemiologia e Serviços de Saúde, $17,2,135-137$.

Silva, L. F. S. C., \& Mocelin, D. G. (2009). Satisfação com o emprego em call centers: novas evidências sobre o emprego trampolim. Revista Psicologia, 9, 2, 60-71.

Silva, M. B. d., Oliveira, M. B. d., \& Fontana, R. T. (2011). Atividade do mototaxista: riscos e fragilidades autorreferidos. Revista Brasileira de Enfermagem, 64, 6, 1048-1055.

Silva, R. B. (2010). Motoboys em São Paulo: Gestão da vida nos circuitos da circulação no espaço. GEOgraphia, 12, 24, 75-107.

Soares, D. F. P. P., Mathias, T. A. F., Silva, D. W., \& Andrade, S. M. (2011). Motociclistas de entrega: algumas características dos acidentes de trânsito na região sul do Brasil. Revista Brasileira de Epidemiologia, 14, 3, 435-444.

Valot, C. (2007). O transporte, a segurança e a ergonomia. In P. Falzon (Ed.), Ergonomia (pp. 573-586). São Paulo: Edgar Blucher.

Vasconcelos, R., \& Lacomblez, M. (2005). Redescubramo-nos na sua experiência: O desafio que nos lança Ivar Oddone. Laboreal, 1, 1, 38-51. 
Veronese, A. M. (2004). Moto-boys de Porto Alegre: convivendo com os riscos de acidentes. Dissertação de Mestrado em Enfermagem, Universidade Federal do Rio Grande do Sul, Porto Alegre.

Vidal-Gomel, C., Delgoulet, C., \& Geoffroy, C. (2014). Competências coletivas e formação em condução de veículos de socorro num contexto de especialização de bombeiros sapadores em França. Laboreal, 10, 1, 14-31.

\section{ABSTRACTS}

A small number of researches on motorcycle couriers investigated the conditions and types of work organization and their effects on the workers. Little is known about the employees' characteristics in this profession. Therefore, it was aimed to analyze the entrance, permanence and abandonment of the work in this profession and its subjective and collective effects. It is a quanti-qualitative study, involving 189 workers, and accomplished using instruments and research techniques orientated by Ergology, and mobilizing approaches from the Activitycentered Ergonomics, Psychodynamics of work and Activity Clinic. The results reveal aspects that contribute to the entrance, abandonment or permanence in this profession: characteristics of work, workers' living conditions, personal and social relations network and possibility of selfconstruction through work. It was concluded that the professional trajectories diversity in this occupation hinders the consolidation of professional collective, requiring from public organizations policies on formation, health promotion and quality of life.

o reduzido número de pesquisas sobre motoboys investigou as condições e formas de organização do trabalho e seus efeitos sobre trabalhadores. Pouco se pesquisou sobre as características das pessoas que exercem a profissão. Assim, objetivou-se analisar o ingresso, permanência e abandono do trabalho nesta profissão e seus efeitos subjetivos e coletivos. Tratase de estudo quanti-qualitativo, envolvendo 189 motoboys, realizado por meio de instrumentos e técnicas de investigação com orientação da Ergologia, mobilizando abordagens da Ergonomia da Atividade, Psicodinâmica do Trabalho e Clínica da Atividade. Os resultados revelam aspectos contribuintes para o ingresso, abandono ou permanência na profissão: características do trabalho, condições de vida dos trabalhadores, rede de relações pessoais e sociais e possibilidade de produção de si por meio do trabalho. Concluiu-se que a diversidade de trajetórias profissionais dificulta a consolidação do coletivo profissional, requerendo de órgãos públicos políticas de formação, promoção da saúde e qualidade de vida no trabalho.

El número limitado de investigaciones sobre mensajeros motociclistas indagó las condiciones y formas de organización del trabajo y sus efectos en los trabajadores. Pero se han realizado pocas investigaciones sobre las características de las personas en la profesión. Así, se tomó como objetivo analizar el ingreso, la permanencia y el abandono del trabajo en esta profesión y sus efectos subjetivos y colectivos. Se trata de un estudio cuantitativo y cualitativo, con una muestra de 189 participantes, empleando técnicas de investigación basadas en la Ergología, movilizando la Ergonomía de la Actividad, la Psicodinámica del Trabajo y la Clínica de la Actividad. Los resultados resaltan los aspectos que contribuyen al ingreso, la permanencia o a la salida en el oficio: características del trabajo, condiciones de vida de los trabajadores, red de relaciones personales y sociales y posibilidad de construcción de sí por el trabajo. Se concluye que la diversidad de trayectorias profesionales dificulta la consolidación de un colectivo de trabajo, requiriendo de los organismos públicos políticas de formación, promoción de salud y calidad de vida en el trabajo. 
Un nombre restreint de recherches a analysé l'activité des courriers motocyclistes, les conditions et formes d'organisation du travail auxquelles ils se confrontent et leurs effets sur les travailleurs. Et peu ont étudié les caractéristiques des personnes qui exercent la profession. La recherche présentée dans cet article a analysé l'entrée, la permanence et l'abandon du travail dans cette profession et les effets subjectifs et collectifs de ces parcours. L'étude, quanti-qualitative, a engagé 189 sujets et a recouru à des dispositifs théorico-méthodologiques guidés par l'Ergologie tout en mobilisant l'Ergonomie de l'Activité, la Psychodynamique du Travail et la Clinique de l'Activité. Les résultats révèlent des aspects décisifs pour entrer, rester ou quitter la profession : caractéristiques de l'activité, conditions de vie des travailleurs, réseaux de relations personnelles et sociales, et possibilité de production de soi-même par le travail. On conclut que la diversité des parcours empêche la consolidation du collectif professionnel. Des impératifs en résultent pour les organismes publics sur le plan des politiques de formation, de la promotion de la santé et de la qualité de vie au travail.

\section{INDEX}

Palavras-chave: motoboy, profissão, coletivo de trabalho, constituição de si, acidentes de trabalho

Keywords: motorcycle courier, profession, work group, self-constitution, work accidents Mots-clés: courriers motocycliste, profession, collectif du travail, constitution de soi, accidents de travail

Palabras claves: mensajero motociclista, profesión, colectivo de trabajo, construcción de sí, accidente de trabajo

\section{AUTHORS}

\section{THIAGO DRUMOND MORAES}

Núcleo de Estudos e Intervenção em Trabalho e Saúde (NUTRAS), Programa de Pós Graduação em Psicologia, Departamento de Psicologia, Universidade Federal do Espirito Santo (UFES), Av.

Fernando Ferrari, 514, Vitória - ES, Brasil

thiago.moraes@ufes.br

\section{ROSEANE VARGAS ROHR}

Grupo de estudos e pesquisas em Arte, Ciência e Cuidado em Saúde, Departamento de Enfermagem - Centro de Ciências da Saúde, Universidade Federal do Espirito Santo (UFES), Av. Marechal Campos, 1468, Vitória - ES, Brasil roseane.ufes@gmail.com

\section{MILTON ATHAYDE}

Grupo de Pesquisa Actividade, Instituto de Psicologia - Universidade do Estado do Rio de Janeiro, Pesquisador do CNPq, Rua Duvivier, 18, ap. 601, Rio de Janeiro - RJ, Brasil athayde.milton@gmail.com 